\title{
De inimigos a bons amigos? os Camacã e o Barão Fernando Steiger no quadro da interiorização da colonização na província da Bahia ${ }^{1}$
} From Enemies to Good Friends? The Camacã
and Baron Fernando Steiger in the Framework of the
Interiorization of Colonization in the Bahia Province

Ayalla Oliveira Silva*

Resumo: Este artigo trata das tensões sociopolíticas e das relações étnicas estabelecidas no processo da interiorização da colonização no sul baiano, durante a segunda metade do século XIX. O objetivo é analisar, por meio da correspondência particular do barão Fernando Steiger, a aliança que um grupo Camacã estabeleceu com o barão na expectativa de manter a sua segurança e a sua sobrevivência na região, que era, à época, objeto preferencial da colonização provincial, o que impactava profundamente a vida dos povos indígenas. Palavras-chave: Camacã; Fernando Steiger; Colonização; Relações étnicas.

\begin{abstract}
This article deals with sociopolitical tensions and ethnic relations established in the interiorization process of colonization in southern Bahia, during the second half of the nineteenth century. The aim is to analyze, through the private correspondence of the baron Fernando Steiger, the alliance that a Camacã group established with the baron in the expectation of maintaining their safety and survival in the region that was, at the time, the preferred object of provincial colonization, which deeply impacted the lives of indigenous peoples.

Keywords: Camacã; Fernando Steiger; Colonization; Ethnic Relations.
\end{abstract}

Na segunda metade do século XIX, a colonização da região sul da Bahia mereceu atenção privilegiada quando se discutiu o tema da colonização provincial. Tal atenção envolvia, em primeiro lugar, a expectativa em torno do cacau, já que a região era avaliada como detentora das melhores terras ao seu cultivo. O cacau foi consolidado como monocultura de exportação, chegando

\footnotetext{
* Universidade Federal do Oeste da Bahia (UFOB), Barreiras, BA, Brasil. ayallasilva@yahoo.com.br $<$ https://orcid.org/0000-0002-5425-9718>
} 
a corresponder, em início do século XX, a mais da metade da receita da Bahia (Falcón, 2010), alçando o sul do estado ao patamar de uma das principais regiões exportadoras de cacau do mundo (Mahony, 2001). Também não podemos desprezar a crise socioeconômica resultante da prolongada seca que abateu, principalmente, o norte da província, em 1857 (Gonçalves, 2000) - cenário no qual o deslocamento populacional ao sul foi uma das alternativas implementadas pelo poder público baiano (Lyra, 1982). Em paralelo, as autoridades provinciais relacionavam o controle da região à presença e à ação dos índios, que representavam o real empecilho à efetiva colonização daquela porção da Bahia.

$\mathrm{Na}$ segunda metade do Oitocentos, a província implantou o projeto da colonização nacional no sul da Bahia, com vistas à ocupação não indígena e à exploração econômica regional, bem como à nacionalização dos índios não aldeados habitantes da região (Silva, 2020). Colonização e indigenismo, portanto, figuraram como pautas imbricadas destinadas à zona sul. Segundo tal processo, a pacificação, a terra e o trabalho dos indígenas se convertiam em aspectos centrais nas dinâmicas políticas, econômicas e sociais, no sul da Bahia, durante a segunda metade do século XIX (Silva, 2018; 2020), envolvendo-se muitos e diversos atores sociais, assim como acontecia em outras realidades do Império (Dornelles, 2017).

A região ora apresentada nesse artigo compreendeu um corredor regional de trânsitos, de sociabilidades, de comércio, de viabilização da ocupação pelos colonos e de intensas relações étnicas, ligando o litoral sul da Bahia ao norte de Minas Gerais, que se manteve central por, pelo menos, um século. Esse corredor regional era formado pelos rios Pardo, Cachoeira e Salgado; pela estrada Ilhéus-Vitória; por pequenas localidades; por fazendas; pelos aldeamentos São Pedro de Alcântara (Ferradas), Barra do Salgado, Catulé, Cachimbo e Lagoa; e pela colônia nacional Cachoeira de Ilhéus (vide Figura 1).

Há mais de duas décadas, os estudos histórico-antropológicos sobre os povos ameríndios definiam as sociedades indígenas como produtos históricos dos processos coloniais e pós-coloniais, como afirmaram Oliveira (1996) e Boccara (2001). Filiado a essa abordagem já consolidada, este texto tem por objetivo apresentar e analisar tanto o processo de contato e interação estabelecido entre um importante fazendeiro da Ilhéus oitocentista e um grupo Camacã, no quadro da interiorização da fronteira de ocupação e exploração econômica do sul baiano, quanto as dinâmicas elaboradas no mesmo processo. 
Figura 1: Mapa do corredor regional Ilhéus -Vitória - Minas, século XIX
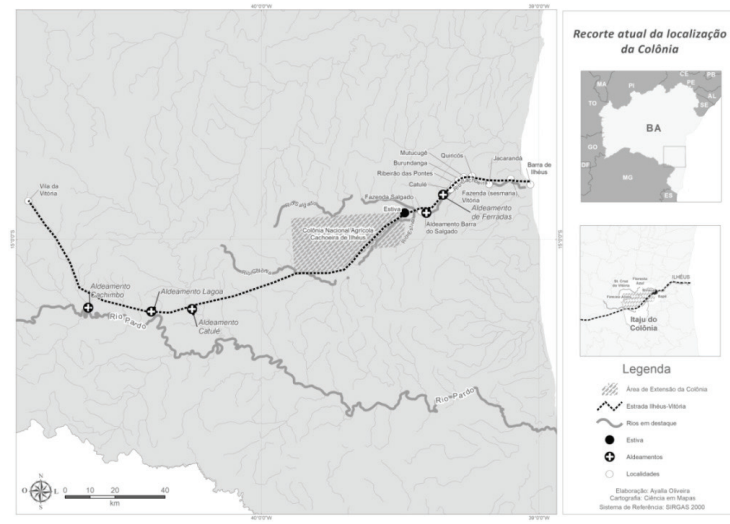

Fonte: Silva, 2020.

Neste quadro, o barão Fernando Steiger se converteu em uma figura importante, tornando-se também peça-chave para a compreensão da trajetória histórica de parcela dos indígenas no sul da Bahia.

A documentação de análise inédita e privilegiada nesse artigo compreende parte das missivas do barão Fernando Steiger, escritas em francês e alemão e endereçadas aos seus interlocutores na Europa, disponíveis na Biblioteca da Burguesia de Berna (Burgerbibliothek Bern), na Suíça, cotejadas por uma biografia de Steiger escrita por seu irmão Albert Steiger, bem como por outras fontes de naturezas diversas ${ }^{2}$. Em tais cartas, Steiger tratava de assuntos que iam desde o cotidiano familiar até aspectos da vida política do Império. Interessam-me especialmente as cartas da década de 1870, nas quais o barão dispensou atenção às relações étnicas e às negociações estabelecidas entre ele e os indígenas.

Na composição da história dos povos indígenas no Brasil, não é comum se encontrar esse tipo documental que dá tantos e tão importantes testemunhos sobre as tensões, as negociações e os limites da relação entre indígenas e não indígenas. Nesse sentido, as missivas de Steiger iluminam pontos que a documentação administrativa, em geral, possibilita que percebamos de forma muito limitada. Permitem-nos acompanhar de perto parte das experiências indígenas na região que era simultaneamente de expansão da fronteira agríco- 
la, de colonização, uma "fronteira étnica" (Barth, 2011) e uma "zona de contato" (Pratt, 1999) entre índios e não índios, entre índios aldeados e índios não aldeados e entre índios aliados e índios inimigos dos colonos e dos fazendeiros.

Fernando Steiger era suíço, oriundo da nobreza bernense, e chegou a Ilhéus em 1846, para administrar uma grande e destacada fazenda pertencente a um parente. Em 1851, já à frente da fazenda Vitória, parecia bem articulado ao poder local quando se casou com Maria Amélia de Sá Bittencourt, inserindo-se na família Sá Bittencourt Câmara, uma das mais influentes da Bahia e de Minas Gerais, do período colonial e imperial.

João Ferreira Bittencourt e Sá se estabeleceu em Camamu, comarca de Ilhéus, em meados do século XVIII. Ao participar do processo de remoção dos jesuítas na Bahia, passou a controlar grande parte das antigas posses jesuíticas na comarca de Ilhéus (Mahony, 1996, p. 90). José de Sá e Bittencourt Câmara Accioli, um dos seus sobrinhos, após os estudos em Coimbra, retornou à Minas Gerais. Em razão do conturbado desdobramento da sua participação nos acontecimentos em torno do movimento político que ficou conhecido como "Inconfidência Mineira”, José Sá se estabeleceu na vila de Ilhéus e se tornou o mais importante proprietário de terras da comarca e também um esforçado aliado da Coroa no que dizia respeito ao plano de desenvolvimento econômico voltado à região (Mahony, 1996, pp. 100-101).

Ao defender o seu plano de desenvolvimento regional, José de Sá e Bittencourt Câmara evidenciou à Coroa que o êxito de tal projeto dependia da abertura de uma estrada que ligasse o litoral sul da Bahia ao norte de Minas Gerais, o que exigia, por conseguinte, a pacificação dos povos indígenas habitantes da região. A insistência em abrir aquela estrada tinha como foco central proporcionar a colonização na região e dinamizar os negócios da família. $\mathrm{O}$ projeto de José Sá foi continuado pelos seus filhos: o brigadeiro José de Sá Bittencourt e Câmara e o seu irmão, o coronel Egídio Luís de Sá Bittencourt e Câmara, ambos envolvidos nos planos de colonização e indigenistas voltados à zona sul da Bahia, durante a segunda metade do século XIX (Silva, 2020).

Fernando Steiger, que se casou com Maria Amélia de Sá, filha de Egídio Luís de Sá, em 1856, comprou do seu parente May Hünger a fazenda Vitória, inserindo-se, também ele, no projeto da família Sá voltado à região. Após instalar-se definitivamente em Ilhéus, Steiger passou a escrever cartas à família e a outros correspondentes na Europa. Nas missivas enviadas ao pai e ao 
irmão, entre junho de 1862 e abril de 1865, Steiger relatou sucessivas perdas na lavoura de café e na lavoura de algodão da fazenda Vitória, provocadas, sobretudo, pelo ataque de pragas que devastaram as suas plantações. Em consequência das sucessivas safras arruinadas de café e algodão, ocorridas nos anos 1860, Steiger voltou a sua atenção ao cacau e dedicou esforços na expansão da ocupação de terras para plantar cacaueiros.

Na biografia que Albert Steiger escreveu sobre o seu irmão Fernando Steiger, em 1891, ele revelou que a plantação da Vitória se limitou ao cacau, afirmando que seu "irmão tinha gradualmente plantado 200.000 pés [de cacau], cerca de 1.600 pés por hectare de solo" (Fa Von Steiger, 1891)3. A partir de então, Steiger extrapolou as fronteiras da Vitória e fundou uma nova fazenda a aproximadamente $50 \mathrm{~km}$ dela - se tratava de uma zona interiorana do rio Cachoeira ainda pouco ocupada pela frente de expansão da colonização.

Em 1860, o arquiduque austríaco Maximiliano de Habsburgo, que visitou o Brasil na qualidade de primo de Pedro II, foi recebido por Fernando Steiger na fazenda Vitória. O arquiduque partiu de Vitória com a sua comitiva, com destino ao interior da zona atlântica, no rio Cachoeira, em Ilhéus, que fazia parte do roteiro expedicionário naturalista de Maximiliano ao Brasil. Foi acompanhando Maximiliano que Steiger passou a ter interesse em explorar comercialmente a região interiorana localizada no curso do rio Salgado. Para atingir o seu propósito, Steiger contatou e negociou, com funcionários e autoridades do governo, tanto na vizinha vila de Canavieiras quanto em visita à Salvador, como indica excerto da carta que escreveu ao irmão Albert, em junho de 1868:

O propósito era requisitar, junto ao engenheiro do governo instalado em Canasvieiras, a aquisição, se possível a doação, de algumas milhas quadradas de terra junto ao Rio Salgado. E eu possuo as melhores chances de atingir o meu objetivo de ser encarregado de abrir uma estrada de Salgado à Vitória, um trabalho com cujas próprias despesas, de outra forma, eu teria de arcar. No próximo navio a vapor, irei até a Bahia apresentar ao presidente da província os meus planos e requisições, e se as coisas ocorrerem como desejadas, irei, com algumas cinquenta pessoas selecionadas, para as selvas de Salgado, para realizar por lá o trabalho preparatório, além de atar as conexões diplomáticas com os botocudos que ainda habitam por lá (Fa Von Steiger, 1868).

Steiger conseguiu colocar em prática o seu projeto. Naquele mesmo ano, estava responsável pelo trabalho de abertura e manutenção da estrada Ilhéus- 
-Vitória, utilizando, inclusive, a mão de obra dos índios do aldeamento de Cachimbo, localizado no rio Pardo e dirigido pelo capuchinho Luiz de Grava grande articulador dos interesses públicos e privados no que concernia ao indigenismo praticado na região (Seção colonial e provincial, APEB, 1868). A estrada - ou parte dela - já existia, mas recorrente e rapidamente era tomada pelo mato. Já as “conexões diplomáticas" com os botocudos, se existiram, foram rapidamente abandonadas, posto que não fossem nada diplomáticas as relações travadas pelo barão com aqueles "índios inimigos” (Fa Von Steiger, 1878a).

Fernando Steiger compartilhou com o irmão Albert os percalços enfrentados para a instalação da fazenda Salgado, em uma carta que lhe remeteu em 1870. Steiger adotou um tom dramático ao expor as dificuldades enfrentadas, chegando a presumir não resistir por muito tempo aos danos que a incursão à floresta causou à sua saúde: “[...] Veja bem, o Salgado fez muitas vítimas [ele se referia à febre amarela]. Eu sou apenas a ruína do que costumava ser. Mas eu não esquivo! E eu sinto muito por morrer agora; estou aguentando até que tenha feito alguma coisa de Salgado". Apesar das queixas a respeito do estado de saúde, ele seguiu narrando, de forma entusiasmada, os resultados alcançados, exaltando a diminuição de incidência da febre amarela entre os escravizados, a existência abundante de água potável e a fertilidade da terra daquela localidade. Era, finalmente, o triunfo da "civilização" sobre a "floresta primitiva" (Fa Von Steiger, 1870b).

Nas férteis terras do Salgado, Steiger privilegiou o plantio de produtos agrícolas de exportação: o café e o cacau, para os quais ele já havia começado a preparar as terras da floresta. Contudo, Steiger tinha por certo que o sucesso do seu empreendimento dependia das relações que ele fosse capaz de estabelecer com os indígenas habitantes daquela região. Porque, além de pouquíssimo habitada por não indígenas, tal região compreendia uma zona historicamente marcada pela resistência dos pataxós e dos botocudos ao avanço da fronteira agrícola sobre os seus territórios.

\section{DE “inimigos” A “BONS AMIgOs”}

Em abril de 1870, Fernando Steiger remeteu uma carta a Barrelet, encarregado da educação dos seus filhos na Europa. Na ocasião, Steiger dedicou 
parte dessa carta a narrar ao seu interlocutor como se deram as relações estabelecidas por ele com os camacãs, na região entre os rios Salgado e Pardo:

Os índios selvagens [camacãs] - que haviam sido por mim expulsos de suas artimanhas favoritas, nas áreas de Salgado ricas em pescas e caças, e de cujas hostilidades eu sempre me apavorava - são agora meus bons amigos. Eu havia partido na véspera de natal a fim de passar a semana com a família na Fazenda Vitória, deixando em Salgado uma guarnição de não mais do que seis homens negros. Estava há apenas três dias em Vitória, quando um destes negros chegou com a notícia de que os índios haviam invadido Salgado no dia de natal, que havia uns cinquenta deles, e que queriam ver-me de qualquer maneira (Fa Von Steiger, 1870a).

Os indígenas retornaram imediatamente à mata, ao serem informados da ausência do "grande chefe de Salgado" ou "grande chefe branco", que, segundo Steiger, era como os indígenas se referiam a ele. Porém, mataram porcos, galinhas e colheram milho, abóbora e mandioca para se alimentar, antes de seguirem a sua jornada. Ao ser informado e rapidamente retornar à Salgado, Steiger não encontrou o grupo e partiu ao seu encontro. Depois de alguns dias de viagem, o alcançou já no rio Pardo. Um "velho" que compreendia e falava português era o chefe do grupo e intermediou a comunicação do mesmo com o barão. Após a mediação do "chefe" e a sua permanência junto aos indígenas por alguns dias, Steiger retornou a Salgado acompanhado de cerca de 30 jovens, e explicou qual era a sua pretensão ao reunir o grupo: "construir para eles uma vila a meia légua do meu estabelecimento, empregá-los para limpar a floresta e para mostrar-me os lugares onde houvesse ipecacuanha [erva medicinal $]^{4}$ em abundância e, quem sabe, até mesmo mostrar-me depósitos de ouro" (Fa Von Steiger, 1870a).

Fernando Steiger exibiu claramente quais eram os seus objetivos ao tentar assentar os indígenas nas proximidades da fazenda Salgado: utilizar o conhecimento que eles tinham sobre a região, bem como dispor da sua força de trabalho. Mas o plano de Steiger foi fracasso pelo fato de os índios não pretenderem se fixar em Salgado, pois eles retornaram para junto dos parentes no rio Pardo, dos quais se separaram quando aceitaram acompanhar o barão, que montou a sua expedição apenas com os homens jovens. Se o barão deu pouca atenção ao fato de os índios se separarem das suas famílias, eles, ao contrário, parecem ter se oposto a isso e, consequentemente, ter frustrado Steiger. 
Na biografia que Albert Steiger escreveu, finalmente conseguimos ter pistas sobre a identificação étnica daquele grupo indígena. Tratava-se dos camacãs, mais precisamente dos camacãs do aldeamento de Ferradas ${ }^{5}$, pois Albert mencionou o episódio descrito acima e acrescentou que Fernando já tinha visitado os camacãs "juntamente com o arquiduque Maximiliano, e dera presentes a eles" (Fa Von Steiger, 1891). Albert se referia à ocasião em que Fernando Steiger acompanhou a comitiva expedicionária do seu hóspede Maximiliano àquela zona da Mata Atlântica, momento no qual o último visitou o aldeamento de Ferradas e permaneceu entre os camacãs por dois dias. Nos seus registros de campo, Maximiliano relatou o encontro com os camacãs, confirmando a informação de Albert acerca da oferta dos presentes aos indígenas (Maximilian, 2010 [1864], p. 239).

Em outra ocasião, Steiger revelou que o "velho" cacique com quem ele estabeleceu negociação no rio Pardo era o mesmo que havia conhecido em Ferradas, em 1860 (voltaremos a esse encontro adiante). Por ora, é importante salientar que, se parte dos camacãs, além do cacique, era conhecida de Steiger da época em que ele estivera em Ferradas junto com Maximiliano, esses camacãs (ou parcela deles) vinham de uma trajetória de experiências com os "processos de territorialização" (Oliveira, 2016).

Apesar de os camacãs terem frustrado os planos de Steiger ao retornarem ao interior da mata, ele havia conquistado algo igualmente importante, que era manter a segurança de Salgado através da aliança firmada com os indígenas. Isso porque Steiger seguiu narrando a Barrelet que havia estabelecido uma boa relação com aqueles camacãs e que eles já o tinham visitado algumas vezes em Salgado. Frisou, além disso, a importância de não os ter como inimigos, em vista da preocupação constante que ele tinha com a segurança da fazenda, em face dos ataques dos botocudos e dos pataxós. Nas suas palavras: “[...] Felizmente, eles parecem manter a amizade do Grande Chefe de Salgado, que é como eles me chamam" (Fa Von Steiger, 1870a).

A interpretação que faço acerca do processo até aqui alinhavado é a seguinte. Em 1868, quando Fernando Steiger começou a explorar comercialmente o rio Salgado, os camacãs que se mantinham na região, provavelmente dispersos após o abandono administrativo do aldeamento de Ferradas, entraram em colisão com ele - ocasião em que os indígenas foram compelidos a abandonar aquela zona devido às investidas do fazendeiro e se refugiaram no rio 
Pardo. Apesar do passado conflituoso entre os camacãs e o barão, eles retornaram ao rio Salgado em 1870 - em razão da sua permanência instável no rio Pardo, devido às disputas territoriais interétnicas - dispostos a se encontrar e a negociar com aquele que se impôs como o "grande chefe de Salgado".

Em fins dos anos 1870, Steiger dividia com os seus correspondentes as preocupações e aventava a possibilidade de vender a fazenda Salgado, em vista do rigor que as viagens entre Salgado e Vitória impunham à sua já frágil saúde, mas não só. O motivo principal do seu desânimo era a intensificação dos ataques dos botocudos à Fazenda. Esse processo se deu no contexto de recrudescimento da guerra impetrada pelos botocudos e pataxós à frente de expansão na região Ilhéus-Vitória (Silva, 2021). Para tentar assegurar a manutenção da fazenda, Steiger buscou obter o socorro dos seus "índios amigos":

[...] Agora, no entanto, os meus aliados, os camacães, passaram a gostar de mim, da localidade e da vida um pouco civilizada, consideram-se também aqui mais seguros das investidas dos patachós e dos mongojós [mongoiós] e pediram-me para assentar por aqui as suas moradas. Dei-lhes um terreno a aproximadamente meia hora do meu estabelecimento, construí cabanas e providenciei as demais instalações. Um dos meus maiores prazeres agora é subir o rio navegando de canoa até uma linda cachoeira, numa área esplêndida, em cujos dois lados está posicionada a minha colônia militar (Fa Von Steiger, 1878a).

O antigo desejo de Fernando Steiger - instalar os seus "aliados camacãs" nas proximidades da sua Fazenda - finalmente foi realizado. A implementação do projeto foi viabilizada pelo interesse dos camacãs em se instalar em terras do Salgado controladas pelo "grande chefe", em contexto de maiores conflitos com os pataxós e com os mongoiós no rio Pardo. Dessa vez, se deslocaram acompanhados de mulheres, crianças e idosos. Em troca de proteção e condições materiais de sobrevivência em Salgado, os camacãs se dispuseram a atuar como braço armado na "colônia militar" que Steiger construiu às margens do Rio. De certo modo, aquela aliança se constituiu em uma relação recíproca de proteção.

Acerca da referência de Steiger aos mongoiós como inimigos dos camacãs, devemos observar o que definiu Maria Hilda Paraíso. Segundo a autora, os camacãs eram referidos como "Kamakã-Mongoió" ao norte do rio Pardo, mas não se pode afirmar se "Kamakã-Mongoió" era uma "auto ou heterodenomi- 
nação". Sugere-se, portanto, que Mongoió fosse uma variação dos Camacã. Ainda segundo Paraíso, os camacãs não se davam bem com os pataxós e os botocudos, que teriam se deslocado para o seu território tradicional e eram recorrentemente usados contra os seus inimigos pelos conquistadores (Paraíso, 2014, p. 188).

Não foram estabelecidas colônias militares no sul da Bahia na segunda metade do XIX, projeto que, em outras partes do Império, foi central para a colonização de áreas interioranas e para a promoção da pacificação indígena nessas regiões (Brüggemann, 2013; Silva, 2020). Apesar disso, Steiger foi bem claro ao afirmar que tinha sua própria "colônia militar" indígena, e em explicitar o quanto ela era necessária à segurança de sua vida e dos negócios. Por outro lado, os camacãs aceitaram se estabelecer na colônia que Steiger construiu para eles, como alternativa de retorno ao território do rio Salgado (rico em caça, pesca e coleta), e também para se livrarem dos ataques dos seus rivais, no rio Pardo.

\section{Cacique Tijanta, muito mais que um "Príncipe destronado"}

Em todo esse percurso supracitado, uma figura se destacou de forma discreta, mas surpreendente. Foi no processo de juntar as pequenas peças localizadas nos diferentes arquivos a fim de montar um mosaico suficientemente inteligível às minhas perguntas, que fui me aproximando dessa personagem central para pensar a experiência daquele grupo camacãs na região. $\mathrm{O}$ que se segue, portanto, é a tentativa de acompanhar mais de perto o itinerário do velho cacique que negociou com Steiger em nome dos camacãs. Ainda em um excerto da carta referida acima, o barão fez a seguinte descrição do cacique:

É aquele mesmo cacique que, há dezenove anos, apertou a mão do arquiduque Maximiliano com a sua pata sebenta. Ele havia sido foragido de sua morada por tribos inimigas, impelido às redondezas desabrigado, quando o encontramos por acaso em Las Feradas (Fa Von Steiger, 1878a).

Ainda em 1878, Steiger novamente fez referência ao "velho cacique" Camacã de Ferradas, em carta que ele escreveu ao cunhado Charles, em Berna. 
A aparição mais imponente é a do velho cacique, que deve ter uns oitenta anos. No mínimo um metro e oitenta de altura e possui uma dentição de causar inveja a qualquer um. Nenhum fio de cabelo branco sequer. $O$ único que possui alguma compostura humana. É o mesmo que apertou a mão do Arquiduque Max e o tratou como "meu primo", causando ao príncipe uma grande diversão (Fa Von Steiger, 1878b).

No segundo caderno de campo, Maximiliano registrou as informações sobre Ferradas, onde a comitiva chegou a 20 de janeiro de 1860: "[...] Cerca de cinco horas [...]. Exigência de silêncio! Chegada à praça São Pedro de Alcântara" (Maximilian, 2010, p. 236). Ao descrever os primeiros momentos da visita, Maximiliano não deixou de anotar que o "capitão Francis (Tijanta)" e o seu filho Roberto sentaram-se ao lado dos visitantes, mas indiferentes a eles. Ainda completou com a seguinte informação: "almoço com as últimas sobras, presentes para os índios, beijam a mão, menos capitão Francis” (Maximilian, 2010, pp. 237-239). Tijanta saudou o Arquiduque com um aperto de mão e o tratou de "meu primo", conforme nos informou Steiger. O que pareceu inusitado e divertido aos nobres visitantes, revelava a alteridade do cacique. Joseph Selleny, renomado artista naturalista austríaco que acompanhou a comitiva de Maximiliano, dentre as muitas gravuras que elaborou, nos legou o desenho do capitão Tijanta, conforme Figura 2.

Figura 2: Desenho do cacique capitão Francis Tijanta

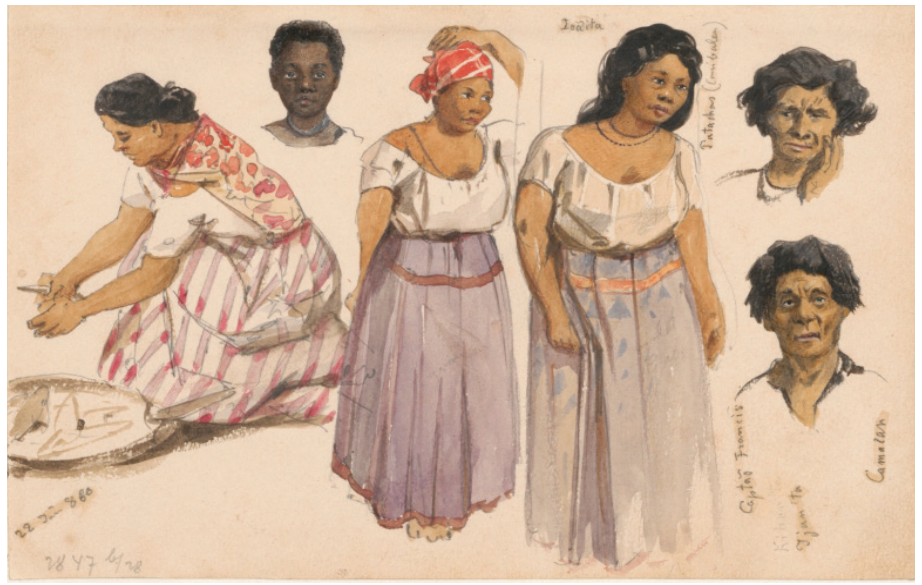

Fonte: Selleny, 1860. 
O desenho compõe o acervo de Selleny na Biblioteca Nacional da Áustria, em Viena (disponível no acervo digital da Biblioteca). A gravura trazia a legenda "Escravos e escravas negros", apesar dessa informação, ela compõe um quadro étnico bastante variado, o que salienta a complexidade das interações étnicas em Ferradas. Selleny deu destaque, contudo, ao lado direito do desenho, no qual as pessoas estão devidamente identificadas: "Joanita" (filha de Tijanta); um homem Pataxó: "Patachós (Canibalen)", referência aos pataxós como "canibais"; e o "capitão Francis Tijanta Camacan".

Na gravura, Tijanta aparenta algumas características já descritas por Steiger, cuja feição corresponde àquela de um senhor na faixa de 50 a 60 anos de idade. Se levada em conta tal digressão, essa característica condiz à média de idade que Steiger lhe atribuiu dezoito anos depois, na carta de 1878, já mencionada.

Importante dar destaque à descrição trazida no desenho: "capitão Francis Tijanta Camacan”. Em nenhum dos seus registros Maximiliano se referiu a Tijanta como indígena. Selleny, ao contrário, não deixou de registrar que ele era Camacã. Essa informação é importante, porque nos permite recuperar as diferentes facetas do seu percurso na região: capitão Francis Tijanta, Tijanta ou "velho cacique" Camacã.

Segundo Fernando Steiger, o velho cacique havia sido expulso da sua habitação pelos índios inimigos e compelido a ir com a sua família (Joanita e Roberto) para Ferradas. O arquiduque Maximiliano, por esse motivo, o apelidou de "príncipe destronado", dedicando-lhe até um poema: O Príncipe Destronado, o qual compõe os anexos de Mato Virgem.

\section{[...]}

Quis saber por que tanta indiferença,

Do velho cansado e mudo ante a bela natureza:

Príncipe dos Kamakã, todo poderoso,

Foi ele o senhor desse esplêndido lugar.

[...]

Cacique, desconhecia cuidados ou desditas.

As armas e a canoa, orgulhoso, dominava.

Seus filhos, como senhor, ele casava

Com as noivas que em guerra conquistava. 
Contando nos dedos as travadas lutas,

Ousadas guerras, ricas em presas e vitórias.

Porém um dia, chegaram os Botocudos,

Com astúcia, aproximaram-se em segredo,

Tal ondas turvas de violentas águas

Inundaram a linda terra dos Kamakã [...]

(Maximilian, 2010, pp. 232-233).

O Tijanta do imaginário poético de Maximiliano é uma figura apática, que parece já não desejar viver. A imagem que o lápis de Selleny traçou e congelou no papel desenhado me causa uma sensação não muito diferente: são rostos tristes, olhares ermos e vazios. O lápis e o papel dos ilustres estrangeiros parecem refletir o fracasso ao qual acreditavam estarem destinados os povos indígenas.

A narrativa de fracasso e a imagem de "violentos assassinos" para caracterizar os indígenas, não são incomuns no discurso de padres, autoridades e intelectuais nas experiências coloniais. Elas escamoteiam duas questões importantes à análise dos povos indígenas na história do Brasil. Por um lado, a avaliação de que eles estavam destinados a morrer física ou etnicamente; um discurso que foi constituído no XIX e reverberado na narrativa histórica ao longo do XX (Freyre, 2003[1933]; Prado Júnior, 1963[1942]; Hemming, 2007[1978]). Por outro lado, a atribuição de violência por Maximiliano aos botocudos, que ecoava um discurso geral sobre eles, encobria e eximia a própria violência nos processos de dominação a que eles eram submetidos. Atribuía a guerra indígena exclusivamente aos próprios indígenas, que eram acusados de agir segundo a sua "natural inclinação má", como definiu o próprio "diretor dos índios do rio Pardo", frei Luiz de Grava (1874).

Se lidas a contrapelo, essas fontes imprimem a Tijanta um nome, uma feição, uma personalidade e, o mais importante, uma trajetória que parcialmente conseguimos acompanhar. Revelam, ao contrário de uma figura apática e resignada, o vigor com que o cacique mobilizava forças dezoito anos depois daquele encontro, a sua enorme capacidade de articulação numa fronteira extremamente fluida e instável entre o mundo dos índios e o dos não índios. Expõem também o preconceito e o extremo rancor de Steiger em rela- 
ção à dignidade e à altivez do capitão, referindo-se ao aperto de mão como um encontro entre a mão de um arquiduque e a "pata sebenta" de um cacique.

A essa altura, nos chama a atenção a referência ao cacique Tijanta como "capitão". Nesse sentido, é importante ressaltar que a inclusão dos índios como força militar foi uma das estratégias do poder da Metrópole para tornar possível a efetiva colonização na Colônia. Os índios recrutados nos aldeamentos coloniais e os índios aliados dos portugueses integravam a força militar na Colônia e desempenhavam papel fundamental nas guerras de conquista, merecendo a concessão de benefícios na condição de vassalos da Coroa. Um exemplo, neste sentido, é Antônio Felipe Camarão, agraciado com as mais altas mercês e patentes militares, dentre outros benefícios régios, pelos importantes serviços militares prestados nas lutas de conquista durante o século XVII, legando aos seus descendentes o mesmo prestígio gozado junto à Coroa (Lopes, 1998, pp. 143-144).

Com a criação da Guarda Nacional, em 1831, em substituição às Ordenanças, os índios continuaram integrando as divisões militares nos interiores do Império, utilizando-se das patentes que recebiam conforme seus códigos sociais e interesses. É possível que o capitão Tijanta tenha atuado no Destacamento da Cachoeirinha do Rio Pardo, estabelecimento militar que funcionou no sul da Bahia até o início da segunda metade do XIX e que mantinha comunicação com o aldeamento de Ferradas (Rego, 2014; Silva, 2020).

Importante salientar que os líderes indígenas mantinham grande mobilidade entre os aldeamentos e os espaços e atividades militares. Hipólito Perret, um francês que fez uma excursão ao sul da Bahia e permaneceu entre os indígenas de Ferradas durante algum tempo, escreveu uma série de artigos sobre os camacãs no noticiário semanal O Crepúsculo (que circulava em Salvador), entre 1845 e 1846. Em um desses artigos, ele registrou que um dos chefes de Ferradas, o qual residia na mata, havia visitado o então diretor do aldeamento (frei Ludovico) com um "séquito" de uma dúzia de índios, todos carregando consigo ornamentos característicos das fardas militares - tais como "fitas e galões” (Perret, 1846, p. 58). Nas fardas militares, as dragonas eram utilizadas como elementos distintivos das altas patentes, enquanto os galões distinguiam os oficiais de mais baixa patente (Barroso, 1938, p. 56).

A minha hipótese é de que o capitão Tijanta se tratava de um desses líderes que viviam entre Ferradas e outros espaços na região. Além disso, era co- 
mum aos aldeados de Ferradas viverem independentes do centro administrativo do aldeamento, causa de inúmeras queixas por parte de Ludovico de Livorno às autoridades provinciais (Silva, 2018). É tentador também considerar a hipótese de que o "chefe" referido por Perret fosse o próprio cacique capitão Tijanta. Por que não?

A intensa trajetória do Cacique, ou capitão Francis Tijanta, nas matas entre Ferradas, Salgado e o rio Pardo, traduz a sua grande interação com o mundo da colonização. O trânsito por ele empreendido lhe permitia negociar em favor próprio e dos demais camacãs, em um contexto de extrema violência, porque os conflitos existentes não eram apenas entre as etnias, como fazia crer o discurso colonial. Nessa ocasião, os indígenas eram o alvo principal de um projeto de colonização em prática no sul da Bahia. Nesse processo, os índios não aldeados estavam expostos à violência dos particulares, também a coerções e a capturas forçadas orientadas pelo então diretor dos índios do rio Pardo, frei Luiz de Grava, com anuência das autoridades provinciais que de tudo eram inteiradas, por meio dos relatórios que Grava lhes remetia (Silva, 2020).

INSTRUMENTALIZAÇÃO DO CONFLITO E DETRAÇÃO ÉTNICA

Fernando Steiger aproveitou, em favor próprio, o conflito interétnico envolvendo os indígenas localizados entre os rios Cachoeira e Pardo (camacãs, mongoiós, botocudos e pataxós). Conflito que havia sido intensificado pelo avanço da fronteira de ocupação, agrícola e pecuária na região. Steiger montou a sua guarda indígena e promoveu uma retaliação violenta contra os "índios inimigos", por meio da aliança estabelecida com os "índios amigos". Como ele próprio escreveu:

Estes haviam sofrido bastante com os meus inimigos e ficaram contentes em poder se vingar. Eu forneço-lhes rifles e munição em lugar dos arcos e flechas que eles utilizam, pago os tiros em dinheiro por cada homem que eles matam (mulheres e crianças não são contabilizados), assim, em pouco tempo fui liberto daqueles malvados (Fa Von Steiger, 1878a).

A guerra entre os grupos étnicos fazia parte das suas relações socioculturais, mas sofreu drástica mudança a partir dos processos de colonização, quando a guerra indígena foi instrumentalizada pelos europeus - um exemplo foi 
o Tupi contra os "tapuias”, os índios “inimigos” dos portugueses. Para Juliana Fujimoto, com a efetiva colonização da América portuguesa, "as alianças luso-indígenas foram gradualmente substituídas pela submissão dos indígenas aos missionários, aos colonos e à administração colonial"; circunstância em que os missionários jesuítas ocuparam o lugar central de mediadores culturais entre os índios e a administração colonial, "a fim de adaptar os indígenas para atender às demandas da colônia por terra e escravos" - razões pelas quais “as alianças bélicas com os indígenas tornaram-se instrumentalmente úteis nas margens da colônia" (Fujimoto, 2016, p. 228).

O principal pano de fundo do conflito que ficou conhecido como "guerra dos bárbaros", envolvendo os denominados “tapuias”, no nordeste brasileiro, durante o século XVII, era a expansão da fronteira para a economia pastoril. Nas investidas das campanhas militares contra os "índios inimigos", participaram, além de pretos e degredados, os índios aldeados e os índios "aliados" dos portugueses (Puntoni, 2002, pp. 132-136). A instrumentalização da guerra indígena foi recorrentemente atualizada pela administração e pelos particulares ao longo dos séculos seguintes, a exemplo de Fernando Steiger, que se aproveitou do conflito interétnico e deu arma de fogo aos seus "índios aliados", para que eles as utilizassem contra os seus "inimigos em comum". Para ratificar esta conduta, ele escreveu: "Enquanto escrevo, há uma meia dúzia de índios de pé em frente à minha varanda. É que eu precisei formar uma guarda-de-corpo desta cambada para proteger-me [...]. Meus índios já fizeram diversas incursões contra os nossos inimigos em comum, e provavelmente já mataram uma dúzia." (Fa Von Steiger, 1878b).

Similar ao que acontecia em outras províncias do Império, no sul da Bahia da segunda metade do século XIX, o emprego da brandura e da violência sobre os indígenas eram práticas articuláveis, quando o assunto era fazer avançar as frentes de expansão. Dito de outro modo, em detrimento da "brandura" para lidar com os índios ante o decreto 426, de 1845, as práticas adotadas nessas regiões interioranas do Império eram bem outras, pois se convertiam em espaços em que pacificar e exterminar eram faces de um mesmo processo (Monteiro, 2001, p. 143).

Pelo visto, a "amizade" entre o barão e os camacãs havia chegado ao fim. $\mathrm{O}$ rompimento se deu à revelia da vontade do primeiro. $\mathrm{O}$ agravamento dos ataques provocados, dentre outros, pelos pataxós, à Salgado e à estrada, possi- 
velmente compeliu os camacãs a abandonarem, em 1879, o estabelecimento que Steiger havia criado para eles, pois a "colônia militar" havia deixado de representar segurança para os camacãs. De fato, em fins de 1878, Steiger reclamava da inconstância dos seus "índios amigos". No entanto, para ele, que via os indígenas como incapazes intelectualmente, era improvável imaginar que os camacãs pudessem pensar objetivos e traçar planos quando aceitaram fixar-se em Salgado. Steiger atribuía o comportamento aparentemente volúvel dos seus "amigos" às ideias de liberdade que chegavam aos "seus índios e negros" e os tornavam "desobedientes":

A tal dita liberdade e igualdade está atualmente cuspindo em todas as cabeças, penetrando inclusive dentro das selvas, entre as tribos indígenas selvagens, que não respeitam mais os seus chefes e atiram neles [...]. Até mesmo os meus, que eu queria transformar um pouco em gente, fugiram preferindo a vida animal livre a uma outra qualquer. Só o velho chefe permaneceu fiel a mim e lamenta agora sobre a depravação da raça humana. Até com os negros não é mais tão simples assim de se lidar. Como se sabe, muitas leis aqui são escritas sem que pessoa alguma as siga. Em todo caso, o conhecimento de tais leis, todavia, torna o escravo rebelde (Fa Von Steiger, 1878c).

A historiografia dos estudos da escravidão há muito demonstrou que as pessoas escravizadas sempre lançaram mão de estratégias e negociações para lograr a sua liberdade na situação do cativeiro (Chalhoub, 1990). No entanto, as leis de emancipação dos anos finais da escravidão no Brasil transformaram a prática costumeira em instrumento legal, tal como a lei de setembro de 1871, que garantia aos homens e às mulheres escravizados o direito à "alforria" e ao "pecúlio" (Perussatto, 2010, p. 149).

Eram a tais leis emancipacionistas que Steiger fazia referência quando relatou a Albert a rebeldia indígena e escrava provocada por ideias de "igualdade e liberdade”. Ele já havia dirigido ao irmão a sua avaliação às leis emancipacionistas de então. Em 1875, por exemplo, Steiger escreveu a Albert revelando o que pensava da lei promulgada em 1871. Na sua avaliação, a lei deu todas as garantias e os privilégios aos negros diante do seu senhorio, e aos negros eram concedidos tantos direitos humanos que não havia mais direitos aos brancos (Fa Von Steiger, 1875) 6

Em demonstração da rebeldia dos "seus índios", Steiger reiterou a Albert 
que a sua "guarda-de-corpo pele vermelha" o havia abandonado completamente (Fa Von Steiger, 1879). A seguinte frase sintetiza bem o que o Barão pensava dos seus "amigos" camacãs que transitaram entre Ferradas, Salgado e o rio Pardo: "Esses [os "índios inimigos"] e meus antigos semisselvagens são como ratos e gatos. Quem quiser ser poupado de ratos deve conservar os gatos; estes são, porém, frequentemente, tão desagradáveis quanto os próprios ratos" (Fa Von Steiger, 1879).

Essa frase revela quanto o "grande chefe de Salgado" repudiava e desprezava os "seus índios", considerados por ele como seres "incorrigíveis", apesar das suas assertivas nas cartas acerca de tentar “civilizá-los”. A ideia de civilização dos camacãs que Steiger defendia era a de treiná-los ao trabalho nos termos da pedagogia catequética colocada em prática pelos capuchinhos italianos (Amoroso, 2014, pp. 102-104). A não submissão dos camacãs ao trabalho sedentarizado na fazenda era, talvez, a maior frustração de Fernando Steiger na relação de "amizade" construída entre eles.

De modo geral, no conjunto das cartas enviadas aos seus correspondentes, Steiger se referia aos camacãs de maneira extremamente depreciativa, a exemplo do excerto que se segue:

É óbvio que sou recebido [na colônia militar] com tanta alegria quanto permite a fleuma colossal dessa gente animalesca; a alegria é mais devido às doações de aguardente e tabaco que trago comigo do que pelo "grande chefe branco" por si só. Você tem que ser um bom príncipe. A propósito, é uma gente horrenda: cabeça grande, barriga grande, membros longos e finos, perfis de uns verdadeiros macacos, quem os vê tem que concordar com Darwin. [...] Em toda a parte, somente aquela bestialidade repelente (Fa Von Steiger, 1878a, grifo do autor).

A teoria cunhada por Darwin em A origem das espécies, a partir de 1859, foi disseminada nas divergentes interpretações no debate sobre raça em voga neste contexto. As disciplinas sociais "utilizaram as propostas e os conceitos básicos da obra para a análise do comportamento das sociedades humanas" (Schwarcz, 1993, p. 73) - uma visão “darwinista-social” de fins do XIX e início do XX, que adaptou os procedimentos científicos naturais em substratos de constructos racistas, fundamentados em "determinismos biológicos" (Munanga, 1999). A fala de Fernando Steiger, que evocou Darwin para definir os camacãs como primatas ou seres bestiais, está situada nesse interim da interpre- 
tação social dos fundamentos da teoria de Darwin sobre a evolução das espécies animais e vegetais. Steiger completou:

A única ocupação deles é comer até não poderem mais; em seguida, deitam-se amontoados como porcos e dormem até que a fome os force de volta à comida. Obviamente, são tão estúpidos assim que, em comparação a eles, até o negro mais burro é um gênio. Nem pensar em poder usá-los para qualquer tipo de trabalho leve; tentei de tudo, porém nem mesmo a trindade devocional deles aguardente, tabaco e carne de porco - foi capaz de vencer aquela preguiça. Possuem duas qualidades boas: são obedientes e honestos. Não se pode chamar isto de virtude; são simplesmente comportamentos que resultam do próprio caráter deles. É preciso ter energia para se desobedecer a alguém superior em cada aspecto (Fa Von Steiger, 1878a, grifo do autor).

Steiger recorrentemente mencionou a recusa dos camacãs ao trabalho braçal. Descrevendo-a como inaptidão dos indígenas ao trabalho pela sua incapacidade de aprender e pensar e em função da sua "natural preguiça". A carta revela, uma vez mais, sua imensa frustração por não dispor do trabalho dos camacãs de forma mais proveitosa aos seus interesses. Revela também a posição racista de Steiger, ilustrada na cristalina crença na inferioridade biológica e na incapacidade intelectual dos camacãs.

Embora fosse indesejada, Steiger exercitava o hercúleo esforço de manter uma convivência cotidiana com as famílias camacãs, lhes dava presentes e os convidava para passar os domingos na sua fazenda. É possível perceber na sua narrativa a tensão que tais ocasiões lhe provocavam - a possibilidade da entrada das mulheres e crianças na casa, o toque nos objetos com os "dedos sebentos", a exploração dos ambientes da casa feita por eles lhe consternava. Apesar de não ser possível elaborar uma afirmação por falta de uma análise mais abrangente acerca do universo das missivas, o esforço que Fernando Steiger fazia em manter os camacãs próximos, mesmo contra a sua vontade, indica que ele mantinha uma relação com os indígenas de forma diferente daquela destinada aos escravizados. Por um motivo que considero óbvio: os camacãs eram livres e podiam abandonar a colônia e partir a qualquer momento que lhes conviesse, como de fato o fizeram.

$\mathrm{Na}$ ocasião em que os camacãs apareceram pela primeira vez na fazenda, seguida da incursão de Steiger ao rio Pardo a fim de encontrá-los - momento em que ele permaneceu durante seis dias em companhias dos índios, prova- 
velmente para estabelecer uma relação de confiança com eles -, o barão avaliou as condições de vida dos camacãs nas matas de Ilhéus e projetou um destino pessimista para eles:

Os negros não parecem ter a menor afeição pelos seus filhos. Os anciãos de ambos os sexos servem como besta de carga. Somado a isso, são todos anêmicos, pálidos e inchados. [...] creio que dentro de um século dificilmente se encontrará mais alguns destes índios. Eles morrem em massa. Durante os seis dias que passei com eles, morreram uma idosa e uma criança; e havia uma dúzia deles que não parecia querer sobreviver por muito tempo (Fa Von Steiger, 1870a).

É preciso considerar que a avaliação de Steiger sobre a organização social dos camacãs, como incapazes de estabelecer afeto com as crianças e cuidado com os idosos, passa pelo filtro ocidental-cristão. Mas não é essencialmente a esse aspecto que quero chamar atenção. Note-se, aqui, que "negros" é o nominativo utilizado por Steiger para se referir aos camacãs.

Tendo em vista o interesse de Fernando Steiger pela mão de obra indígena, a referência podia significar a pouca distinção que ele podia fazer entre a figura do escravo e a do indígena no que concernia ao trabalho. Além disso, assim como acontecia em outras regiões do Brasil (Dornelles, 2018), a escravização indígena ainda era uma possibilidade real no sul da Bahia, pois um juiz da vila da Barra do rio de Contas, em 1869, comunicou ao presidente da província, o Barão de São Lourenço, que um grupo de índios "selvagens" havia sido capturado em Ilhéus; cinco deles deixados naquela vila para serem "civilizados”, devendo-se redobrar os cuidados com eles, para que não fossem reduzidos à condição da "servidão ilegal" (Relatório, 1869). Portanto, a expressão utilizada podia significar a recuperação da expressão colonial "negros da terra" no vocabulário do barão (Monteiro, 1994).

Por fim, aceitar manter-se em Salgado sob a tutela de Steiger representou para os camacãs, até certo ponto, a possibilidade de obter um espaço mais seguro às suas vidas, quando grande parte dos indígenas estava sendo empurrada cada vez mais para o interior, e exposta à violência da fronteira de expansão. Também era a possibilidade de se prover de condições materiais de sobrevivência, quando o governo promovia a proposital diminuição dos seus espaços de caça, pesca e coleta a fim de persuadi-los aos estabelecimentos coloniais. Aquele, portanto, foi um contexto no qual os camacãs "amigos de 
Steiger" se metamorfosearam, para citar Celestino de Almeida (2013). Agiram conforme puderam na expectativa de manter a sua segurança e a sua sobrevivência na Região Sul - que era, à época, laboratório privilegiado do projeto de colonização pensado e debatido nos espaços políticos e nas repartições provinciais -, em coalizão com os interesses particulares, que impactavam profundamente a vida daqueles povos no sul da Bahia.

\section{REFERÊNCIAS}

ALMEIDA, Maria Regina Celestino de. Metamorfoses indígenas: Identidade e cultura nas aldeias do Rio de Janeiro. 2a Ed. Rio de Janeiro: Editora FGV, 2013.

AMOROSO, Marta. Terra de índio: Imagens em Aldeamentos do Império. Terceiro Nome: São Paulo, 2014.

BARROSO, Gustavo. História Militar do Brasil. $2^{\text {a }}$ Ed. Companhia Editora Nacional: São Paulo; Rio de Janeiro; Recife; Porto Alegre, 1938.

BARTH, Frederik. Grupos étnicos e suas fronteiras. In: POUTIGNAT, Philippe; STREIFF-FENART, Jocelyne. Teorias da etnicidade: seguido de Grupos étnicos e suas fronteiras. Tradução de Élcio Fernandes. 2a Ed. São Paulo: Ed. UNESP, 2011.

BOCCARA, Guillaume. Mundos nuevos en las fronteras del Nuevo Mundo. Nuevo Mundo Mundos Nuevos [en ligne], Débats, 2001.

BRÜGGEMANN, Adelson André. A sentinela isolada: o cotidiano da colônia militar de Santa Thereza (1854-1883). Dissertação (Mestrado em História) - Centro de Filosofia e Ciências Humanas. Universidade Federal de Santa Catarina, Florianópolis, 2013.

CHALHOUB, Sidney. Visões da Liberdade: uma história das últimas décadas da escravidão na corte. São Paulo: Companhia das Letras, 1990.

DORNELLES, Soraia Sales. A questão indígena e o Império: índios, terra, trabalho e violência na província paulista, 1845-1891. Tese (Doutorado em História) - Instituto de Filosofia e Ciências Humanas. Universidade Estadual de Campinas (UNICAMP). São Paulo, 2017.

DORNELLES, Soraia Sales. Trabalho compulsório e escravidão indígena no Brasil imperial: reflexões a partir da província paulista. Revista Brasileira de História, v. 38, n. 79, pp. 87-108, 2018.

FA VON STEIGER (Weiss). Provisorisch Nr. 6, Berna (Burgerbibliothek Bern). 12 de junho de 1868.

FA VON STEIGER (Weiss). Provisorisch Nr. 6, Berna (Burgerbibliothek Bern). 11 de abril de 1870a. 
FA VON STEIGER (Weiss). Provisorisch Nr. 6, Berna (Burgerbibliothek Bern). 20 de agosto de $1870 \mathrm{~b}$.

FA VON STEIGER (Weiss). Provisorisch Nr. 6, Berna (Burgerbibliothek Bern). 27 de novembro de 1875.

FA VON STEIGER (Weiss). Provisorisch Nr. 6, Berna (Burgerbibliothek Bern). 10 de março de 1878a.

FA VON STEIGER (Weiss). Provisorisch Nr. 6, Berna (Burgerbibliothek Bern). 15 de agosto de 1878b.

FA VON STEIGER (Weiss). Provisorisch Nr. 6, Berna (Burgerbibliothek Bern). 31 de dezembro de $1878 \mathrm{c}$.

FA VON STEIGER (Weiss). Provisorisch Nr. 6, Berna (Burgerbibliothek Bern). 30 de novembro de 1879.

FA VON STEIGER (Weiss). Biografie zu Ferdinand von Steiger. Provisorisch Nr. 1a, Berna (Burgerbibliothek Bern). 1891.

FALCÓN, Gustavo. Coronéis do cacau. Salvador: Solisluna, 2a Ed. Revisada, 2010.

FREYRE, Gilberto. Casa-Grande e Senzala: formação da família brasileira sob o regime da economia patriarcal. 48 Ed. São Paulo: Global, 2003 [1933].

FUJIMOTO, Juliana. A Guerra indígena como Guerra colonial - as representações e o lugar da belicosidade indígena e da Antropofagia no Brasil colonial (séculos XVI e XVII). Tese (Doutorado em História) - Faculdade de Filosofia, Letras e Ciências Humanas. Universidade de São Paulo (USP). São Paulo, 2016.

GONÇALVES, Graciela Rodrigues. As secas na Bahia do século XIX (sociedade e política). Dissertação (Mestrado em História) - Faculdade de Filosofia e Ciências Humanas. Universidade Federal da Bahia, Salvador, 2000.

GRAVA, Luiz de. Seção Colonial e Provincial. Relatório do Diretor Luiz de Grava; Série Agricultura: Colônia Nacional Cachoeira de Ilhéus (1870-1877), maço 4604, Ilhéus (Arquivo Público do Estado da Bahia, APEB). 12 de fevereiro de 1874.

HEMMING, John. Ouro Vermelho: A Conquista dos Índios Brasileiros. Tradução de Carlos Eugênio Marcondes de Moura. São Paulo: Edusp, 2007 [1978].

LEVI, Giovanni. Usos da biografia. In: AMADO, Janaina; FERREIRA, Marieta de Moraes (Orgs.). Usos e abusos da história oral. $8^{\text {a }}$ Ed. Rio de Janeiro: Editora FGV, 2006. pp. 167-182.

LOPES, Fátima Martins. Índios, Colonos e Missionários na Colonização da Capitania do Rio Grande do Norte. Natal: Instituto Histórico e Geográfico do Rio Grande do Norte, 1998.

LYRA, Henrique Jorge Buckingham. Colonos e colônias: uma avaliação das experiências de colonização agrícola na Bahia na segunda metade do século XIX. Dissertação (Mestrado em Ciências Sociais) - Faculdade de Filosofia e Ciências Humanas. Universidade Federal da Bahia. Salvador, 1982. 
MAHONY, Mary Ann. The World Cacao Made: Society, Politics, and History in Southern Bahia, Brazil, 1822-1919. Dissertation (Ph.D. in Philosophy) - Graduate School of Yale University. New Haven, 1996.

MAHONY, Mary Ann. "Instrumentos necessários": escravidão e posse de escravos no sul da Bahia no século XIX, 1822-1889. Afro-Ásia, n. 25-26, pp. 95-139, 2001.

MAXIMILIAN von Habsburg, Ferdinand. Mato Virgem. Tradução, introdução e notas de Moema Parente Augel. Ilhéus: Editus - Editora da UESC: 2010 [1864].

MONTEIRO, John Manuel. Negros da Terra: índios e bandeirantes nas origens de São Paulo. São Paulo: Companhia das Letras, 1994.

MONTEIRO, John Manuel. Tupis, Tapuias e Historiadores: Estudos de História Indígena e do Indigenismo. Tese (Livre Docência) - Instituto de Filosofia e Ciências Humanas, Departamento de Antropologia. Universidade Estadual de Campinas (UNICAMP), Campinas, 2001.

MUNANGA, Kabengele. Rediscutindo a Mestiçagem no Brasil: identidade nacional versus identidade Negra. Petrópolis: Ed. Vozes, 1999.

OLIVEIRA, João Pacheco de. Viagens de ida, de volta e outras viagens: os movimentos migratórios e as sociedades indígenas. Travessia, São Paulo: CEM, v. 9, n. 24, pp. 5-9, 1996.

OLIVEIRA, João Pacheco de. O nascimento do Brasil e outros ensaios: "pacificação", regime tutelar e formação de alteridades. Rio de janeiro: Contra Capa, 2016.

PARAÍSO, Maria Hilda Baqueiro. O tempo da dor e do trabalho: a conquista dos territórios indígenas nos sertões do leste. Salvador: Edufba, 2014.

PERRET, Hipólito. O Crepúsculo, v. 2, n. 16, 25 mar. 1846, p. 58. Disponível em: http:// memoria.bn.br/DocReader/DocReader.aspx?bib=812897\&pagfis=255. Acesso em: 30 set. 2021.

PERUSSATTO, Melina Kleinert. Como se de ventre livre nascesse: experiências de cativeiro, parentesco, emancipação e liberdade nos derradeiros anos da escravidão-Rio Pardo/RS, c. 1860-c. 1888. Dissertação (Mestrado em História) - Programa de Pós-graduação em História, Universidade do Vale do Rio dos Sinos. São Leopoldo (RS), 2010.

PRADO JUNIOR, Caio. Formação do Brasil Contemporâneo. $7^{a}$ Ed. São Paulo: Brasiliense, 1963 [1942].

PRATT, Mary Louise. Os Olhos do Império: relatos de viagem e transculturação. Bauru: EDUSC, 1999.

PUNTONI, Pedro. A Guerra dos Bárbaros: povos indígenas e a colonização do sertão Nordeste do Brasil, 1650-1720. São Paulo: Hucitec; Editora da Universidade de São Paulo; FAPESP, 2002.

REGO, André de Almeida. Trajetórias de Vidas Rotas: Terra, Trabalho e Identidade Indígena na Província da Bahia (1822-1862). Tese (Doutorado em História) 
- Faculdade de Filosofia e Ciências Humanas. Universidade Federal da Bahia (UFBA), Salvador, 2014.

RELATÓRIO que apresentou à Assembleia Legislativa da Bahia o Excelentíssimo Senhor Barão de S. Lourenço, presidente da mesma província, em 11 de abril de 1869. Bahia: Tipografia de J. G. Tourinho, 1969. Relatórios Provinciais Presidenciais (1830-1930). In: Center for Research Libraries. Disponível em: http://ddsnext.crl. edu/titles $/ 165$ ?terms $=$ Bar $\# ? \mathrm{c}=0 \& \mathrm{~m}=49 \& \mathrm{~s}=0 \& \mathrm{cv}=0 \& \mathrm{r}=0 \& \mathrm{xywh}=-881 \% 2 \mathrm{C} 111 \%$ 2C3104\%2C2189. Acesso em: 2 jun. 2021.

SCHWARCZ, Lilia Moritz. O espetáculo das raças: cientistas, instituições e questão racial no Brasil - 1870-1930. São Paulo: Companhia das Letras, 1993.

SEÇÃO COLONIAL E PROVINCIAL. Série Justiça/Correspondências juízes de Ilhéus, maço 2401, Ilhéus (Arquivo Público do Estado da Bahia, APEB). 1868.

SELLENY, Joseph. Schwarze Sklaven und Sklavinnen. 1860. Disponível em: http://data. onb.ac.at/rec/baa13726678. Acesso em: 2 jun. 2021.

SILVA, Ayalla Oliveira. Ordem imperial e aldeamento indígena: Camacãs, Gueréns e Pataxós no sul da Bahia. Ilhéus: Editus, 2018.

SILVA, Ayalla Oliveira. Camacãs, pataxós e botocudos no Sul da Bahia: indigenismo, colonização e etnopolítica (1850-1879). Tese (Doutorado em História) - Instituto de Ciências Humanas e Sociais, Programa de Pós-Graduação em História, Universidade Federal Rural do Rio de Janeiro. Seropédica, 2020.

SILVA, Ayalla Oliveira. A guerra indígena como afirmação da autonomia: o caso dos pataxós e botocudos do sul da Bahia na segunda metade do século XIX. Acervo, v. 34, n. 2, pp. 1-24, 2021.

TEIXEIRA, V. A.; COELHO, M. F. B.; MING, L. C. Poaia [Psychotria ipecacuanha (Brot.) Stoves]: aspectos da memória cultural dos poaieiros de Cáceres - Mato Grosso, Brasil. Revista Brasileira de Plantas Medicinais [online], v. 14, n. 2, pp. 335-343, 2012.

\section{NOTAS}

${ }^{1}$ Este artigo é resultado de minha tese de doutorado, cuja pesquisa contou com financiamento FAPERJ.

${ }^{2}$ A biografia e também as missivas de Fernando Steiger são utilizadas na pesquisa a partir da tipologia "biografia e contexto", elaborada por Giovanni Levi (2006), assumindo, nesse sentido, os limites do uso historiográfico da biografia, aos quais o autor chama atenção. São utilizadas, assim, a fim de preencher lacunas documentais, e pensadas no interstício entre a trajetória individual e o sistema social no qual Steiger se insere.

${ }^{3}$ Os documentos de Fa Von Steiger depositados na Burgerbibliothek Bern, aqui utilizados, foram traduzidos por André Paiva de Figueiredo, salvo informação ao contrário. 
${ }^{4} \mathrm{O}$ interesse pela erva denominada ipecacuanha era comum aos conquistadores pelo seu valor medicinal. Além disso, Steiger tinha noções de medicina, mantendo até mesmo uma espécie de hospital na Fazenda Vitória, onde, segundo ele, socorria pessoas da região, inclusive os índios (cf. Teixeira; Coelho; Ming, 2012). A Psychotria ipecacuanha, também conhecida como poaia, no Brasil, é mais comumente encontrada no Mato Grosso e possui grande valor farmacológico.

${ }^{5} \mathrm{O}$ aldeamento São Pedro de Alcântara ou aldeamento de Ferradas foi um aldeamento colonial tardio implantado às margens do rio Cachoeira na vila de Ilhéus, em 1814, cuja população era principalmente formada por indígenas camacãs. O estabelecimento se converteu em elemento central no que dizia respeito ao acesso ao trabalho indígena e à manutenção da pacificação regional, durante grande parte do século XIX. A partir de 1861, Ferradas sofreu o abandono administrativo. Apesar de os indígenas de Ferradas terem desaparecido da documentação administrativa na condição de "índios aldeados", eles não desapareceram fisicamente; se mantiveram na região e buscaram reorientar as suas vidas de diversas e distintas maneiras, a exemplo do grupo Camacã que acompanhamos no presente texto.

${ }^{6}$ Tradução de Dominik Andrzejewicz Diacon.

Artigo submetido em 13 de abril de 2021.

Aprovado em 30 de junho de 2021. 